\title{
Malocclusion Traits of Yemeni Female School Children
}

\author{
Dr Nabil Muhsen Al-Zubair,' Dr Aussama Almulla² \\ 'Assistant Professor, Department of Orthodontics, Faculty of Dentistry, \\ Sana'a University, Yemen \\ 2Professor of Orthodontics, Faculty of Dentistry, Baghdad University, Iraq \\ Correspondence: Dr Nabil Al-Zubair; email: dr.nabilzubair?@gmail.com
}

\section{ABSTRACT}

Objective: To provide detailed information concerning clinically relevant occlusal traits and prevalence of occlusal anomalies in orthodontically relevant period of dental development.

Materials \& Method: 1501 Yemeni female school children aged 12 years were clinically examined. Overjet was measured to the nearest of $0.5 \mathrm{~mm}$, and sagittal molar relationship were measured. In addition, missing permanent teeth, crowding, spacing, anterior maxillary and mandibular irregularities and anterior open bite were evaluated. Descriptive analysis was carried out to assess the frequency.

Result: $9.1 \%$ female presented with at least one missing permanent tooth. The mean overjet was $2.8 \mathrm{~mm}$, an increased overjet greater than $6 \mathrm{~mm}$ was affecting around 4 per cent of the children. Similarly, spacing and crowding were present in $25.8 \%$ and $30.4 \%$ respectively. Anterior open bite was affected in every tenth child. Molar relations other than Class I were reported in $29.5 \%$ of the sample.

Conclusion: Wide range of orthodontically relevant occlusal traits found in the present study underlines the need for orthodontic screening of children at the age of 12 years or earlier.

Key words: occlusal anomalies, malocclusion, Yemeni female

\section{INTRODUCTION}

Gender equity is a major concern in Yemen. History shows that women have contributed major roles in Yemen. The Queen of Sheba, for instance, is a source of pride for the Yemeni nation. Present-day females however are subject to humanity that reflects mostly agricultural, tribal, and patriarchal traditions. This combined with illiteracy and economic issues have led women to be continuously deprived of their rights as the citizens. Fewer girls are registered in school compared to boys, numerous tend to be over-aged and most drop out before completing basic education. In a similar way, females are also devoid in health facilities including the orthodontic service.

Study and determination of criterion for different ethnic groups is essential to promote accurate diagnosis and treatment planning in orthodontics. Individual with malocclusion could feel problem in social contacts, may lose vocation opportunities and might feel embarrassment about their dental appearance.'

Many studies have been conducted to determine the prevalence of malocclusion in different populations. The malocclusion can be defined as an occlusion in which there is a malrelationship between the arches in any of the planes or in which there are anomalies in tooth position beyond the normal limits. ${ }^{2}$

The prevalence of malocclusion has been reported to vary from 11 to 93\%. These variations are difficult to explain. It may depend on differences in recording approaches, ethnic origin, social class, or age of the examined subjects. ${ }^{3}$ However, diagnostic criteria are the key factors determining the prevalence of malocclusion. ${ }^{4}$

Numerous indices such as IOTN, DAI, and ICON have been developed to rank or score the deviation of malocclusion from the normal. ${ }^{5.6}$ An alternative method to the use of indices is a registration of measurable occlusal characteristics such as crowding, overjet, overbite, crossbite, and others. ${ }^{\text {? }}$

Yemen is a country on the Arabian Peninsula in Southwest Asia and is a part of Middle East. Currently, oral health and in particular the treatment of malocclusion is not a high priority in Yemen. However for planning purposes, valid and reliable information regarding treatment needs of oral conditions and diseases are needed. There are no previous research data on the prevalence of malocclusion of the Yemeni population. The lack of data on prevalence and severity of malocclusion in 
Yemen is likely to affect the effective planning for orthodontic services. Thus the aim of this study was to determine the prevalence of individual malocclusion traits in a sample of Yemeni female school children.

\section{MATERIALS AND METHOD}

A random sample of 1501 female children aged 12-yearold was selected from schools in six randomly selected governorates in Yemen. In each governorate the same multi-stage stratified sampling technique was implemented. Permission was obtained from the general directorate of education and the regional directorate of education in the governorates. All school authorities were contacted and the aim of the study was explained to them to ensure full cooperation.

Children were examined seated in a chair with their head supported in an upright position and the examiner standing in front of the chair. Portable light was used to supplement natural daylight during examination when needed. At the end case sheets were reviewed to ensure accuracy of the recording.
Ten malocclusion traits were recorded which included; missing permanent teeth, crowding and spacing of upper and lower arches, maxillary midline diastema, anterior maxillary and mandibular irregularities, overjet, anterior open bite and sagittal molar relationship. Data were entered to SPSS 13.0. Descriptive analysis was carried out to assess the frequency.

\section{RESULT}

The distribution of missing teeth shows about $9.1 \%$ of total sample had at least one tooth missing. The malocclusion traits recorded by this study are shown in Table 1; crowding was present in $30.4 \%$, while spacing was recorded in $25.8 \%$ of the sample. Anterior mandibular irregularities were noticed in $42.2 \%$ sample as compared to anterior maxillary irregularities which was recorded in $37.2 \%$; among them $7 \%$ had anterior mandibular and maxillary irregularities more than $2 \mathrm{~mm}$. Increased overjet more than $3 \mathrm{~mm}$ was present in $30.7 \%$ of the investigated sample. Out of the total sample, $28.5 \%$ demonstrated abnormal molar relationship. The mean overjet was $2.8 \mathrm{~mm}$; the distribution of total sample according to their overjet values is shown in Figure 1.

Table 1: Malocclusion traits of Yemeni female school children

\begin{tabular}{|c|c|c|c|}
\hline \multicolumn{2}{|c|}{ Parameters } & \multirow{2}{*}{$\begin{array}{c}\mathbf{n} \\
137\end{array}$} & \multirow{2}{*}{$\begin{array}{c}\% \\
9.1\end{array}$} \\
\hline Missing teeth & $>1$ & & \\
\hline \multirow[t]{3}{*}{ Crowding (incisal segments) } & 0 & 1045 & 69.2 \\
\hline & 1 & 296 & 19.7 \\
\hline & 2 & 160 & 10.7 \\
\hline \multirow[t]{3}{*}{ Spacing (incisal segments) } & 0 & 1114 & 74.2 \\
\hline & 1 & 278 & 18.5 \\
\hline & 2 & 109 & 7.3 \\
\hline \multirow[t]{2}{*}{ Midline diastema (mm) } & $>1$ & 224 & 14.9 \\
\hline & $>2$ & 39 & 2.6 \\
\hline \multirow[t]{3}{*}{ Anterior maxillary irregularity (mm) } & 0 & 938 & 62.5 \\
\hline & $1-2$ & 455 & 30.3 \\
\hline & $\geq 3$ & 108 & 7.2 \\
\hline \multirow[t]{3}{*}{ Anterior mandibular irregularity (mm) } & 0 & 853 & 56.8 \\
\hline & $1-2$ & 538 & 35.8 \\
\hline & $\geq 3$ & 110 & 7.4 \\
\hline \multirow[t]{4}{*}{ Maxillary overjet (mm) } & 0 & 181 & 12.1 \\
\hline & $1-3$ & 859 & 57.2 \\
\hline & $>3$ & 461 & 30.7 \\
\hline & $>6$ & 57 & 3.8 \\
\hline Open bite (mm) & $>0$ & 138 & 9.2 \\
\hline \multirow[t]{3}{*}{ Molar relationship } & Normal & 1073 & 71.5 \\
\hline & One half cusp & 261 & 17.4 \\
\hline & One full cusp & 167 & 11.1 \\
\hline
\end{tabular}


Figure 1: Distribution of total sample according to overjet values

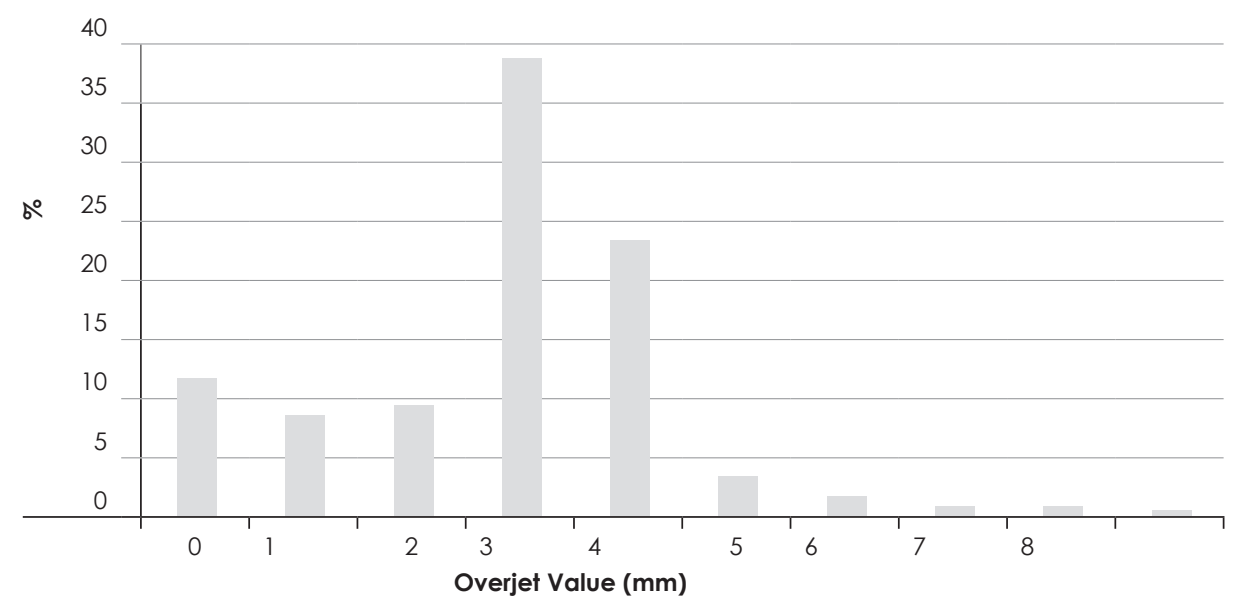

\section{DISCUSSION}

There is no previous study regarding malocclusion in Yemeni population; thus we cannot make any comparison. However, this study will be the first data on the prevalence of malocclusion to form a database for Yemeni studies. Compared to investigations of other countries, the present subjects represent a different population in terms of geographic, social and cultural variations. Comparison with other studies is not always possible because of the differences in descriptions of the examined features, varying examination techniques and different indices. Thus comparison shall be made with the studies carried out on a similar age group using similar methodology emphasizing on the samples of Arabic populations.

The present study suggests that malocclusion in Yemeni school children can be characterized by significant dental crowding and relatively high frequency of missing teeth. In the current study, $9.1 \%$ of had one or more missing anterior teeth in either arch. Similar prevalence was observed by Shivakumar et al. ${ }^{8}$ Only one previous study reporting similar methodology could be found in the Arab literature. In the Iraqi population," the frequency of individuals presenting at least one missing tooth was lower compared to the present report. The higher frequency of missing teeth in the Yemeni school children could be a reflection of the limited access to dental care. The economic constrains could compel the people for least expensive treatment of tooth extraction to solve their dental problems. Dental crowding in at least one dental arch was reported in $19.6 \%$ of Iraqi compared to $30.4 \%$ in the present study. The slight increase in anterior arch dimension during normal development is not sufficient to overcome moderate to severe discrepancies. Crowding is therefore likely to persist in the permanent dentition, particularly if it was initially severe. 11

The present study reports one out of four children presented with spacing in the incisal segment. One of the characteristic features of normal occlusion is arch continuity as expressed by proximal contact between the teeth. The prevalence of spacing in the present study was much higher than that of AlHuwaizi among 13-year-old Iraqi sample. The reason for this difference is the criteria used for the study; as he recorded space discrepancies $\geq 2 \mathrm{~mm}$. However, it was lower than that of Steigman and Weissberg" in 12-14 years old Palestinian sample and of Drummond ${ }^{12}$ in 12-year-old South African sample.

When the diastema larger than $2 \mathrm{~mm}$ is taken into account, the result shows $2.6 \%$ Yemeni females presented with diastema. In the developing dentition of the age 12 years, the presence of diastema is regarded as a normal phenomenon. In the absence of a deep overbite these spaces normally close spontaneously. ${ }^{13}$ If the space between the maxillary central incisors is greater than $2 \mathrm{~mm}$; spontaneous closure is unlikely. 14,15

Brunelle et al $^{16}$ reported that mandibular incisors possess more alignment irregularities than maxillary incisors, which coincide with the present finding, while it contradicts with other studies. ${ }^{8,9,12}$

It is remarkable that, Cons et $a{ }^{17}$ found no irregularities in $92 \%$ of the sample recorded, which may be because they included only irregularities of $2 \mathrm{~mm}$ or more as suggested by Baume et al. ${ }^{18}$ Using the same criteria the present study showed that, $93 \%$ had no maxillary anterior irregularities and $92 \%$ had no mandibular anterior irregularities. This finding supports the previously mentioned finding that slight increase in the anterior arch dimension during normal development is not sufficient to overcome moderate to severe discrepancies. Crowding and anterior irregularities is therefore likely to persist in the permanent dentition. ${ }^{15}$

The mean maxillary overjet of the sample was $2.8 \mathrm{~mm}$, which was smaller than those found in other studies ${ }^{17.19-21}$ but was near to the finding of others.,22 Anterior maxillary overjet 
indicates an antero-posterior deviation in Class II direction. ${ }^{10}$ It was encouraging that, the increased overjet $\geq 6 \mathrm{~mm}$ was found only in $3.8 \%$ of the sample and it was less than the findings of other studies. ${ }^{17,21,23}$

In the present study, 9.2\% children presented with anterior open bite which was four-fold compared to other studies. ${ }^{8,9}$ This difference may be attributed to varying prevalence of oral habits like digit sucking, which have a major role in anterior open bite. In a malocclusion study of 12-13 years old Nigerian children, Otuyemi et a ${ }^{24}$ reported $10.2 \%$ occurrence of anterior open bite in rural and urban communities.

The antero-posterior jaw relation is most often based on upper and lower permanent first molar relation. The right and the left sides were assessed with the teeth in occlusion and the deviation from the normal relation was recorded. ${ }^{25}$ When posterior occlusal relationships were compared between the two populations, molar relations other than Class I were similar in Yemeni and Iraqi school children. ${ }^{8}$

\section{CONCLUSION}

Among the population of Yemeni female school children; malocclusion was characterized by a relatively high frequency of missing teeth, appreciable dental crowding and a relatively high frequency of anterior open bite. The wide range of relevant occlusal traits found in the present study underlines the need for orthodontic screening of children at the age of 12 years or earlier.

\section{OJN}

\section{REFERENCES}

1. Klages U, Bruckner A, Zentner A. Dental aesthetics, self awareness and oral health related quality of life in young adults. Eur J Orthod 2004; 26:507-14.

2. Housten WJ. Walther's orthodontic notes. 4th ed. The Stonebridge Publishers; 2000.

3. Thilander B, Pena L, Infante C, Parada SS, de Mayorga C. Prevalence of malocclusion and orthodontic treatment need in children and adolescents in Bogota, Colombia. An epidemiological study related to different stages of dental development. Eur J Orthod 2001; 23:153-67.

4. Sidlauskas A, Lopatiene K. The prevalence of malocclusion among 7-15-year-old Lithuanian school children. Medicina (Kaunas) 2009; 45:147-52.

5. Onyeaso $\mathrm{CO}$, Begole EA. Orthodontic treatment improvement and standards using the peer assessment rating index. Angle Orthod $2006 ; 76: 260-4$

6. Sayin MO, Türkkahraman H. Malocclusion and crowding in an orthodontically referred Turkish population. Angle Orthod 2004; 74:635-9.

7. Celikoglu M, Akpınar S, Yavuz I. The pattern of malocclusion in a sample of orthodontic patients from Turkey. Med Oral Patol Oral Cir Bucal 2010; 5:791-6.

8. Shivakumar KM, Chandu GN, Subba Reddy VV, Shafiulla MD. Prevalence of malocclusion and orthodontic treatment needs among middle and high school children of Davangere city, India by using Dental Aesthetic Index. J Ind Soc Pedod Prevent Dent $2009 ; 4: 21$ 1-8.

9. Al-Huwaizi AF. Occlusal features, perception of occlusion, orthodontic treatment need and demand among 13-year-old Iraqi school children. Doctorate Thesis, College of Dentistry, University of Baghdad, Iraq, 2002.

10. Proffit WR. Contemporary orthodontics. 4th ed. St Louis; Mosby: 2007.

11. Steigman S, Weissberg Y. Spaced dentition. An epidemiological study. Angle Orthod 1985; 55(20):167-76.

12. Drummond R.J. Orthodontic status and treatment need of 12-year-old children in South Africa: An epidemiological study using the dental aesthetic Index. Master Thesis, College of Dentistry, University of Pretoria, South Africa: 2003.

13. Moyers RE. Handbook of orthodontics, 4th ed. Chicago: Year Book Medical Pub; 1988.

14. Edwards JG. The diastema, frenum, frenectomy: A clinical study. Am J Orthod 1977; 71 (5): 489-508.

15. Proffit WR. Contemporary orthodontics. 3rd ed. St Louis, Mosby; 2000.

16. Brunelle JA, Bhat M, Lipton JA. Prevalence and distribution of selected occlusal characteristics in the US population, 1988-1991. Dent Res 1996; 75: 706-713.

17. Cons NC, Mruthyunjaya YC, Pollard ST. Distribution of occlusal traits in a sample of 1337 children aged 15-18 residing in upstate New York. Int Dent J 1978; 28(2):154-64.

18. Baume LJ, Horowitz HS, Summers CJ, Backer Dirks O, Brown WA, Carlos JP, et al. A method of examining occlusal traits developed by the FDI commission on classification and statistics for oral conditions. Int Dent J 1973; 23: 530-7.

19. Björk A. Variability and age changes in overjet and overbite. Am J Orthod 1953; 39:779-801.

20. Haynes S. The distribution of overjet and overbite in English children aged 11-12 years. Dent Pract 1972; 22(10):380-3.

21. Kinaan BK. Overjet and overbite distribution and correlation: A comparative epidemiological English-Iraqi study. Brit J Orthod. 1986; 13:79-86.

22. Corruccini RS, Lee GTR. Occlusal variations in Chinese immigrants to the United Kingdom and their offspring. Arch Oral Biol 1984; 29(10):779-82.

23. Corruccini RS, Kaul SS, Chopra SRK, Karosas J, Larsen D, Marrow C. Epidemiological survey of occlusion in North India. Brit J Orthod 1983: 10: 44-7.

24. Otuyemi OD, Ogunyinka A, Dosumu O, Cons NC, Jenny J, Malocclusion and orthodontic treatment need of secondary school students in Nigeria according to the Dental Aesthetic Index. Int Dent J 1999; 49(4): 203-10.

25. WHO-Oral Health Survey, Basic methods. 4th ed. New Delhi: AITBS Publishers \& distributors; 1999. 